\section{Surgical revision of dysfunctional filtration blebs with bleb preservation, sliding conjunctival flap and fibrin glue}

\section{Abstract}

Purpose The introduction of anti-metabolite regimens to glaucoma filtration surgery has improved post-operative intraocular pressure (IOP) control; however, it has also increased the frequency of dysfunctional blebs. In this study, we report a surgical technique for the repair of trabeculectomy blebs using bleb preservation, a sliding conjunctival flap, and fibrin glue.

Methods This study is a retrospective, non-comparative, consecutive case series involving 10 eye samples collected from 10 patients (6 M:4 F) with one or a combination of bleb overfiltration, dysesthesia, thinning, leak, or blebitis, in which a conjunctival flap was advanced over the failing bleb and secured in place using fibrin glue and sutures. Results All patient eyes had symptom resolution post-operatively. There were no bleb leaks or hypotonous eyes after an average follow-up of 15.2 months (range: 6-31 months). Three patients required needling augmented with 5-fluorouracil needling to maintain IOP control. IOP decreased from a mean of $13.6 \pm 1.8 \mathrm{~mm} \mathrm{Hg}$ (with a mean of 0.7 glaucoma medications) pre-operatively to

$11.7 \pm 0.9 \mathrm{~mm} \mathrm{Hg}$ (with a mean of 0.9 glaucoma medications).

Conclusion Conjunctival flap advancement with bleb preservation and adjunctive fibrin glue is a successful technique used for the treatment of bleb dysfunction. The major advantages compared with other techniques are preservation of IOP control and reduced post-operative complications, such as wound leak and the need for re-suturing.

Eye (2010) 24, 947-953; doi:10.1038/eye.2009.279; published online 27 November 2009
GA Lee Le, $^{1,3}$ and DJ Holcombe $e^{1,2}$

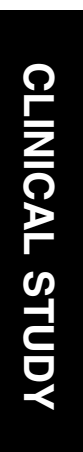

Keywords: dysfunctional bleb; fibrin glue; glaucoma surgery; trabeculectomy

Introduction

The introduction of anti-metabolite regimens to glaucoma filtration surgery has improved postoperative intraocular pressure (IOP) control; however, it has also increased the frequency of bleb leaks. ${ }^{1-3}$ Bleb leaks predispose the patient to serious vision-threatening complications, including hypotony, hypotonous maculopathy, endophthalmitis, and subchoroidal

haemorrhage. ${ }^{4,5}$ Post-anti-metabolite blebs may also become progressively thin and predisposed to overfiltration and blebitis. Conservative treatments such as the use of autologous serum ${ }^{6}$ and blood, ${ }^{7}$ pressure patching, ${ }^{8}$ and aqueous suppression $^{9}$ are usually attempted first to remedy these scenarios; however, successful treatment of dysfunctional blebs often requires surgical revision. Most commonly, surgical revision involves bleb excision with conjunctival advancement, ${ }^{10-17}$ autologous conjunctival grafting, ${ }^{18-22}$ or amniotic membrane transplantation. ${ }^{11,16,23,24}$ The most effective surgical approach to bleb repair remains unclear. Amniotic or autologous conjunctival grafts risk poor healing and graft failure, whereas vascularized conjunctival flaps, although more likely to heal, may undergo retraction and wound dehiscence. Fibrin tissue adhesives are an effective method for opposing wound edges and their use in ophthalmic surgery has broadened. ${ }^{25-28}$ Fibrin glue has been used previously to focally repair bleb leaks, but not as an adjunct to suturing during conjunctival advancement bleb repair. The aim of this paper is to present a series of patients undergoing bleb repair using bleb preservation, conjunctival flap, and fibrin glue.
${ }^{1}$ City Eye Centre, Brisbane, Queensland, Australia

${ }^{2}$ Department of Ophthalmology, Royal Hospital, Brisbane, Queensland, Australia

${ }^{3}$ Department of Ophthalmology, University of Queensland, Brisbane, Queensland, Australia

Correspondence: GA Lee, City Eye Centre, 135 Wickham Tce, Brisbane, Queensland 4000, Australia Tel: +617383 16888; Fax: +617383 16883 . E-mail: eye@ cityeye.com.au

Received: 8 March 2009 Accepted in revised form: 21 August 2009 Published online: 27 November 2009 Brisbane and Women's 


\section{Materials and methods}

A retrospective review of the records of consecutive patients who underwent bleb revision using a sliding conjunctival flap and fibrin glue between January 2006 and September 2008 was undertaken. Institutional board review approval to review patient records without informed consent was obtained. A total of 10 eye samples were included in the study. Surgery was performed by one surgeon (GAL) after obtaining informed consent from the patients, who were identified from the surgeon's patient log. Indications for bleb revision included bleb overfiltration and dysesthesia, bleb thinning, bleb leaks, and blebitis. Conservative measures for bleb leak were undertaken, and cases of blebitis were treated with antibiotics before surgical intervention. Charts were reviewed for demographics, indication for revision, subsequent revision procedures, pre- and postoperative best-corrected visual acuity, pre- and postoperative IOP measurement, the number of pre- and post-operative glaucoma medications, and postoperative complications. A successful outcome was defined as the resolution of the presenting indication for revision, with maintenance of IOP with the same or reduced number of glaucoma medications in the absence of further glaucoma surgery. A qualified success was defined as the resolution of the presenting indication for revision, with maintenance of IOP with increased number of glaucoma medications in the absence of further glaucoma surgery. A failure was considered when surgical revision was deemed necessary for whatever cause (namely recurrent leak, IOP uncontrolled with medication, etc.). Only patients who had more than 6 months follow-up were included in the study.

\section{Technique}

Surgery is performed under local anaesthesia with sedation. A 7/0 polyglactin corneal traction suture aids in superior fornix exposure. The rim around the thin cystic bleb is marked and the conjunctiva was carefully incised, avoiding the bleb. A pair of Vannas scissors can be useful. The dissection is continued sub-conjunctivally over a wide area of the superior fornix until the conjunctival flap can be readily mobilized over the bleb to the limbus with minimal traction. The epithelium at the limbal edge of the bleb is debrided. The epithelium over the bleb is also removed carefully with a microsponge avoiding perforation of the bleb if possible. Areas of bleb overhang can be reduced by excision or wet-field cautery. The conjunctival flap is then mobilized over the bleb and sutured with 10/0 nylon buried horizontal mattress sutures along the edge and purse string sutures at the corners. If there is any conjunctival traction, a relieving incision can be placed high in the fornix (avoiding the lacrimal ductules supratemporally). Fibrin glue (Tisseel Duo 500, Baxter Healthcare, Toongabbie, NSW, Australia) is injected between the conjunctival and Tenon's/bleb plane using a 25-G needle entered high in the fornix avoiding injection into the pre-existing bleb. This needs to be done efficiently as the glue sets rapidly (after $\sim 10 \mathrm{~s}$ ). Post-operatively, topical antibiotics and steroids are administered for 3 months or until the inflammation settles.

\section{Results}

In all, 10 eye samples obtained from 10 patients $(6 \mathrm{M}: 4 \mathrm{~F})$ were included in this study. The mean age of the patients was 67.4 years (range: 54-79 years). All patients had undergone previous trabeculectomy with anti-metabolite augmentation. The average duration from previous trabeculectomy until revision was 7 years (range: 1-12 years). The indications for revision included bleb thinning (five patients; 50\%), bleb overhang and dysesthesia (one patient; 10\%) (Figures 1a and b), bleb leak and blebitis (one patient; 10\%) (Figures 2a-c), bleb leak (one patient; 10\%) (Figures 3a-c), and bleb thinning with blebitis (two patients; 20\%) (Figures $4 a$ and b). Table 1 summarizes the cases. Patients with blebitis and/or leak were resolved conservatively before undertaking bleb repair. Our method of bleb repair using bleb preservation, a conjunctival flap, and fibrin glue, resulted in successful bleb revision in six patients (60\%). Qualified success was achieved in one patient (10\%). None of the patients experienced post-operative hypotony or bleb leak. Needling with 5-fluorouracil (5FU) in addition to glaucoma medication was required in three patients $(30 \%)$ to obtain satisfactory IOP control. The mean duration to failure was 15 weeks (range: 8-21 weeks). The IOP level decreased from a pre-operative mean of $13.6 \pm 1.8 \mathrm{~mm} \mathrm{Hg}$ (SEM; range: $9-25 \mathrm{~mm} \mathrm{Hg}$ ) to a post-operative mean of $11.7 \pm 0.9 \mathrm{~mm} \mathrm{Hg}$ (SEM; range: 6-14 mm Hg). Variability of the IOP depended on the presenting pathology. If there was a leak before repair, the IOP was low and 'normalized' after repair. If the bleb was draining before repair, then the IOP was 'controlled' and ideally remained so after repair. If the bleb before repair was not draining, then the IOP was high, thus potentially requiring further procedure such as needling with 5FU to attain better IOP control.

The average number of IOP medications increased from 0.7 pre-operatively to 0.9 post-operatively. Final best-corrected visual acuity was improved in three patients $(30 \%)$, remained the same in three patients (30\%), and worsened in four patients (40\%). Of these four patients, one worsened from light perception to no perception of light, two went on to further bleb revision 

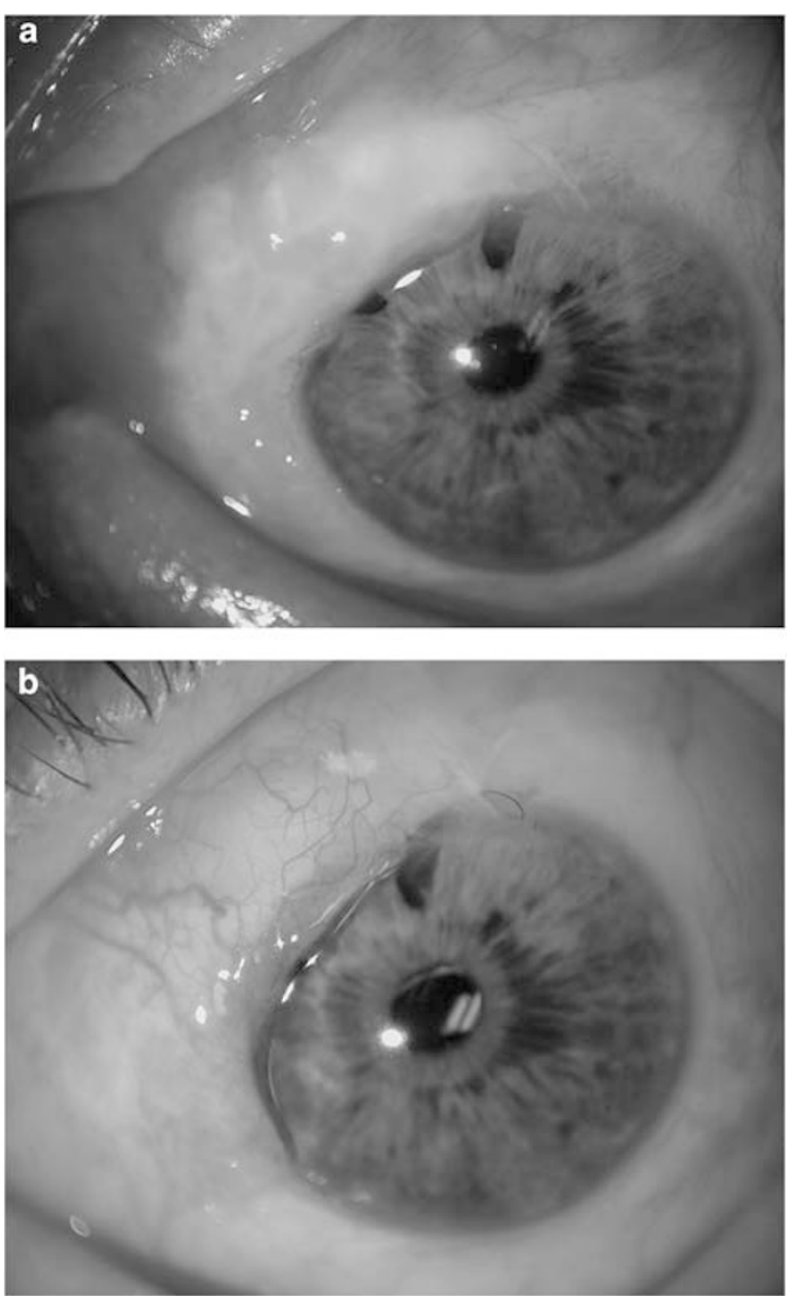

Figure 1 (a) Clinical photograph of patient 1 showing an overhanging thin avascular cystic bleb extending from 7 to 12 o'clock. (b) Clinical photograph of patient 1 at 7 months after bleb repair, showing diffuse drainage and normal vascularization of the bleb.

(5FU needling), and one was managed on topical antihypertensive medication without further bleb revision. The average duration of follow-up was 15.2 months (range: 6-31 months).

\section{Discussion}

Typically, the initial management of leaking blebs involves conservative measures, such as aqueous suppression, ${ }^{9}$ soft bandage contact lenses, ${ }^{29,30}$ autologous serum products, ${ }^{6,7,31}$ or laser treatment. ${ }^{32-34}$ Soft bandage contact lenses have reported success rates of $92-100 \% ;{ }^{29,30}$ however, these lenses are foreign bodies and potentially increase the risk of blebitis and endophthalmitis. Success rates with autologous serum products are lesser. The earliest multi-patient studies have reported success rates of $58-66 \% \%^{35,36}$ for sealing leaking blebs with autologous blood injections, whereas larger and more recent studies have reported the success rate as low as $19 \% .^{7}$ Topical serum was used by Matsuo et $a l^{6}$ to stop aqueous oozing or point-leak through filtering blebs after trabeculectomy. This technique stopped oozing in $62 \%$ of cases and resolved point leaks in $27 \%$ of cases. Intra-bleb autologous platelet injection has also been used effectively in one patient. ${ }^{31}$ Both argon and Nd:YAG lasers have been used to seal bleb leaks. Hennis and Stewart used argon laser and reported a success rate of $86 \%$, whereas Geyer ${ }^{34}$ and Lynch et al ${ }^{33}$ used Nd:YAG lasers with success rates of $64-100 \%$.

The most common surgical approach involves bleb excision with conjunctival advancement., ${ }^{90,12-15,17,37}$ Dunnington and $\operatorname{Regan}^{38}$ first described this technique in two patients who underwent conjunctival advancement for glaucoma bleb leaks. This technique successfully closed the leak, with one of the two patients requiring IOP-lowering drugs after several years of follow-up. In 1992, O'Connor $e t a^{37}$ described a technique in which the scarred bleb was excised and the exposed sclerostomy site was covered by mobilized Tenon's fascia and conjunctiva. Although the authors' claim that the technique was successful in their five patients, no follow-up data was provided. More recent studies have further evaluated the technique. ${ }^{9,10,12-15,17}$ In 1999, Budenz et $a l^{17}$ reported on 26 eyes, in which the failing bleb was excised and the conjunctiva and Tenon's layer superior to it mobilized, and the conjunctiva was advanced into the peripheral cornea. After a mean follow-up of 19.6 months, post-operative leak developed in 12 eyes (46\%) and resolved spontaneously in 7 (27\%) eyes. Five eyes (19\%) required re-suturing and two eyes (8\%) had persistent leaks. There were no cases of persistent post-operative hypotony; however, 13 eyes (50\%) required glaucoma medication and 2 eyes (8\%) required re-operation. Myers et $a l^{15}$ used a similar technique in 16 eyes; however, Tenon's capsule was not mobilized in all cases. After a mean follow-up of 25 months, leaks developed in five (31\%) eyes but resolved spontaneously in four (25\%) with only one eye $(6 \%)$ requiring re-suturing. In all, 10 eyes $(62 \%)$ required glaucoma medication, and there were no cases of persistent hypotony or re-operation. Among the 12 eyes examined by Hamard $e t$ al ${ }^{14}$ during a mean follow-up of 26.7 months, 2 (16\%) developed leaks that became persistent and required re-operation. Six eyes (50\%) required glaucoma medications and there were no cases of persistent hypotony. van de Geijn $e t$ al $^{13}$ reported only three leaks (8\%) in 36 eyes in which both Tenon's capsule and conjunctiva were mobilized; however, all 3 eyes underwent re-operation to repair the leak. There were no cases of hypotony; however, 15 eyes (41\%) required 

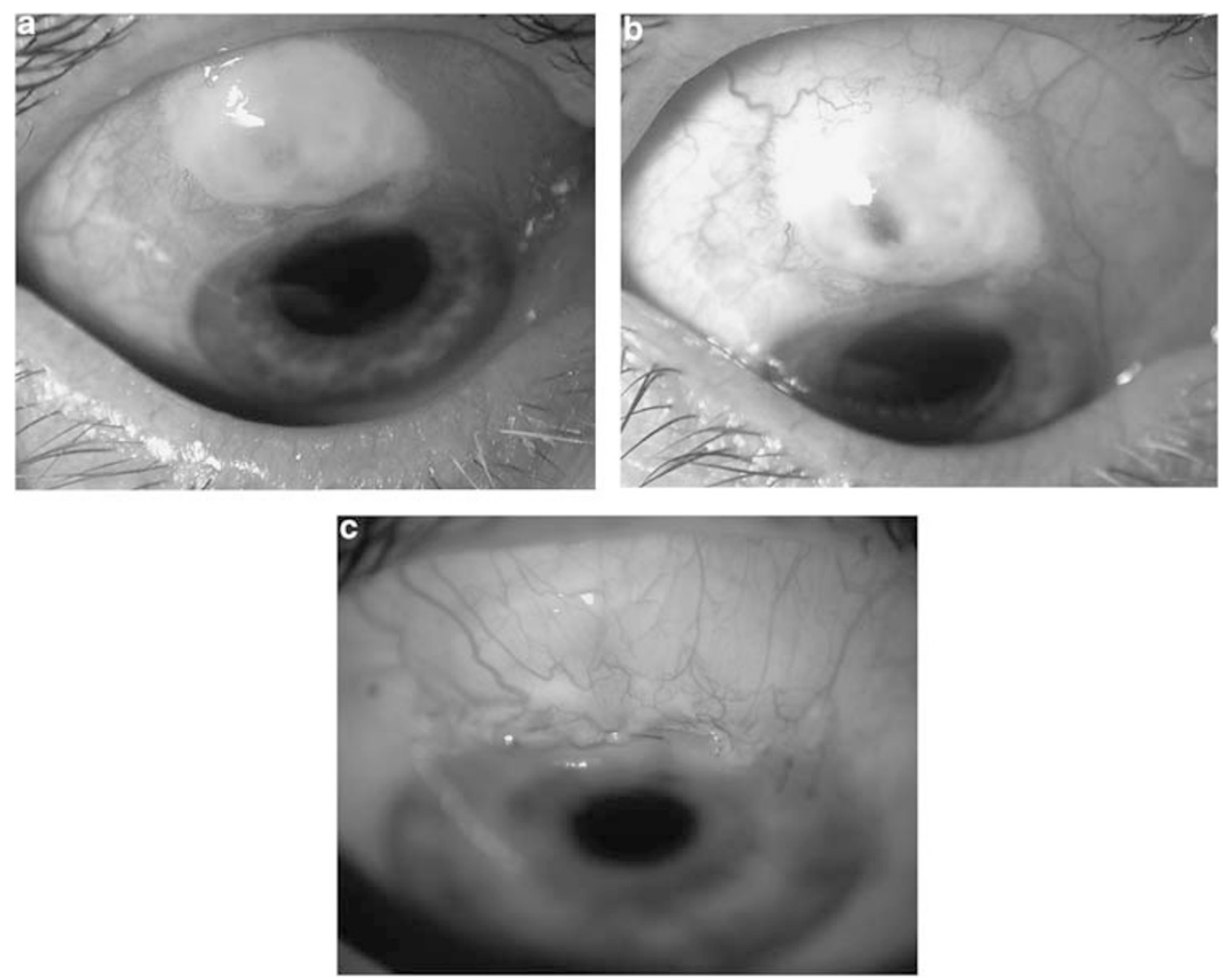

Figure 2 (a) Clinical photograph of patient 4 showing blebitis with haziness of the bleb and intense injection of the conjunctiva. (b) Clinical photograph of patient 4 showing extreme bleb thinning and avascularity after resolution of the blebitis. (c) Clinical photograph of patient 4 at 1 month after bleb repair.
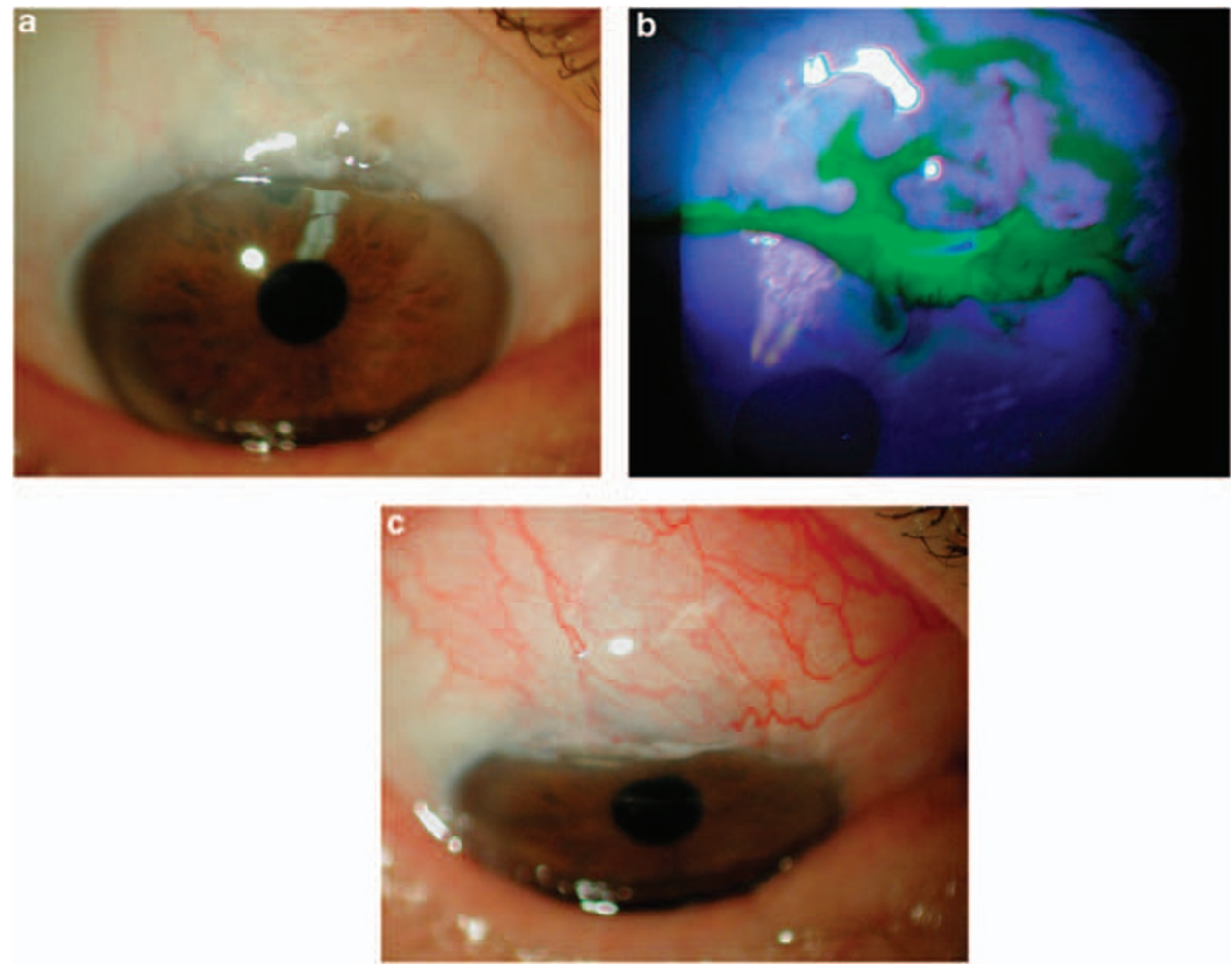

Figure 3 (a) Clinical photograph of patient 6 showing a thin cystic bleb. (b) Clinical photograph of patient 6 showing positive Seidel's sign (arrow). (c) Clinical photograph of patient 6 at 1 month after bleb repair. 

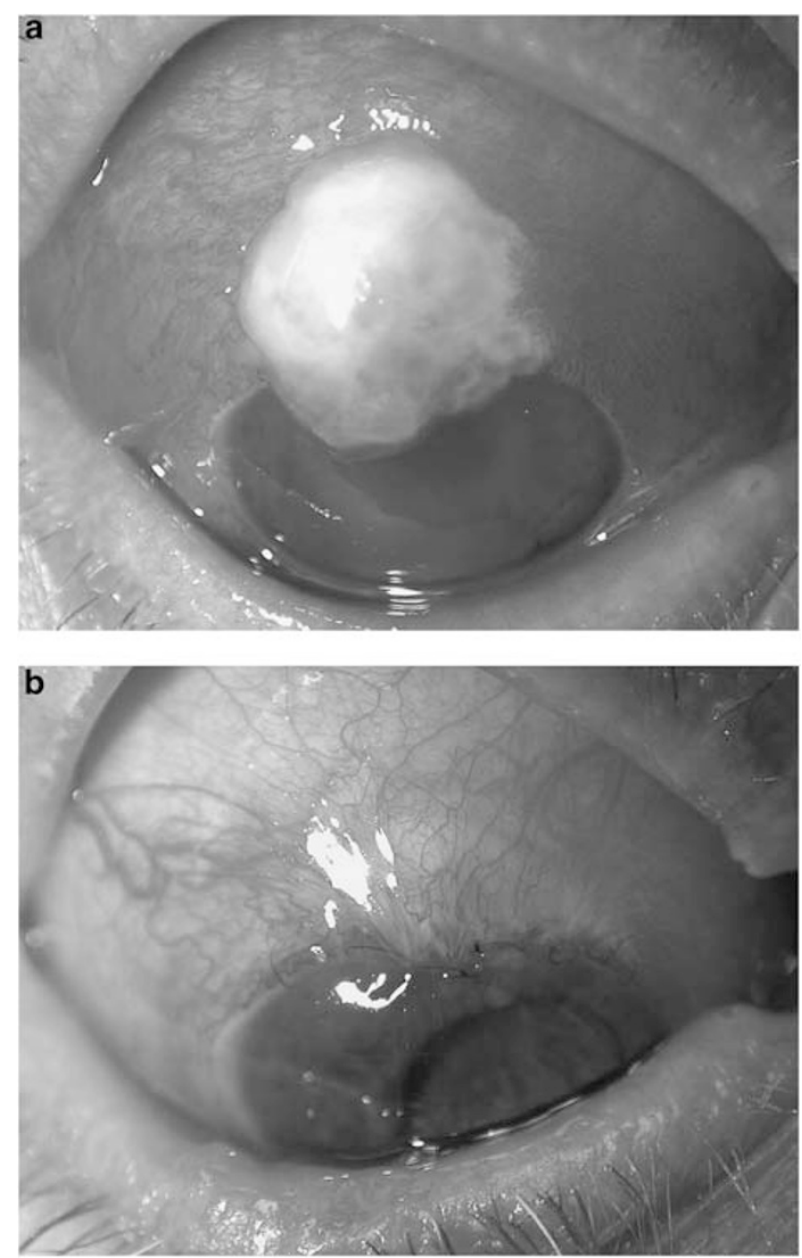

Figure 4 (a) Clinical photograph of patient 9 showing blebitis with haziness of the overhanging bleb and intense injection of the conjunctiva. (b) Clinical photograph of patient 9 at 2 weeks after bleb repair.

glaucoma medication during an average follow-up of 29.5 months. In another large series involving 34 eyes followed up for a mean of 36.2 months, Al-Shahwan et $a l^{12}$ reported leaks in six (17\%) eyes, four (11\%) of which resolved spontaneously, one eye required re-suturing, and one eye was treated with pressure patching. One leak was persistent. There were no cases of hypotony; however, 14 (41\%) eyes required glaucoma medication. Most recently, Spencer et $a l^{10}$ reported a small case series of five eyes undergoing bleb excision and conjunctival advancement for repair. One eye (20\%) developed a leak that resolved with re-suturing. There were no cases of hypotony, and three eyes (60\%) required glaucoma medication during 18.4 months average follow-up.

In eyes for which scarring around the bleb has made conjunctival mobilization impracticable, conjunctival autografts have been used after bleb excision. ${ }^{18-22}$

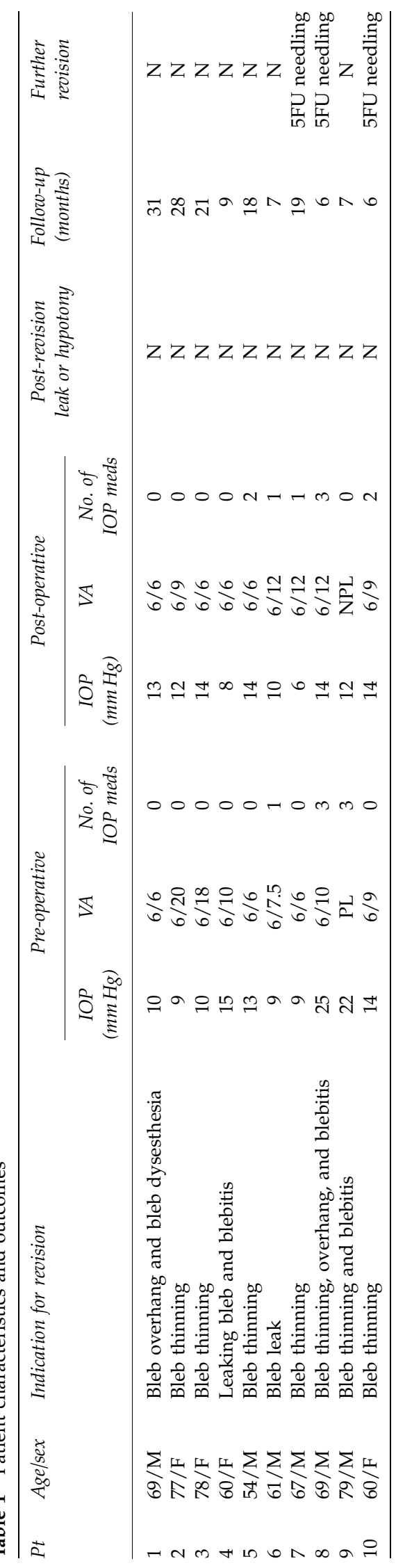


In 1994, Buxton $e t a^{21}$ described a series of five eyes that underwent bleb excision and autologous conjunctival grafting. After an average of 42.6 months, post-operative leakage was observed in only one (20\%) eye and this resolved after re-suturing. No eyes experienced persistent hypotony and only one eye (20\%) required glaucoma medication. Harris $e t a l^{19}$ examined a series of 47 patients with autologous conjunctival bleb resurfacing for persistent conjunctival bleb leaks. Post-operatively, 10 $(21 \%)$ eyes developed leaks. The leaks in three $(6 \%)$ eyes resolved spontaneously, seven (14\%) eyes required re-suturing, and two (4\%) eyes had persistent leaks. No eyes experienced persistent hypotony and two eyes $(4 \%)$ required glaucoma medication. Schnyder et al reported free grafting in 16 eyes. Four eyes (25\%) developed persistent leaks that required re-suturing and one eye (6\%) required re-operation. No eyes developed persistent hypotony; however, six (37\%) eyes required glaucoma medication.

Other authors have investigated the use of amniotic membrane transplants for repairing leaking filtering blebs. ${ }^{11,16,23,24}$ Amniotic membranes have been used successfully in other ocular surface reconstructions and are hypothesized to be advantageous in bleb repair due to its ability to promote epithelialization while suppressing inflammation and scarring. Kee and Hwang ${ }^{24}$ reported the successful treatment of two eyes with leaking blebs without bleb excision by covering the leaking bleb with the amniotic membrane graft. After an average follow-up of 23 months, neither eye developed a leak nor required glaucoma medication. Similarly, AMT grafting was examined in six eyes by Nagai-Kusuhara et $a l^{23}$ One eye required bleb excision; however, the bleb in the remaining eyes was preserved. After a median follow-up of 49 months, there were no recurrent leaks and all patients required glaucoma medication. Budenz et $a l^{16}$ compared amniotic membrane transplantation or conjunctival advancement after bleb excision for leaking filtering blebs. A total of 15 eyes were randomized to each group. After a mean follow-up of 19 months, there were seven failures in the amniotic membrane transplant group - two eyes with late onset leaks, two eyes with persistent leaks, and three eyes that required repeat glaucoma surgery. The conjunctival advancement group was free of such complications.

In this study, we describe a technique for preserving the bleb and re-establishing a healthy conjunctival surface. Catoira et al ${ }^{39}$ used a similar technique of conjunctival advancement with bleb preservation in 27 eyes that were either hypotonous or had a proven bleb leak. After a mean follow-up of 19 months, three eyes (11\%) developed leaks, one leak (4\%) resolved with re-suturing, whereas three eyes $(11 \%)$ required re-operation. Two (7\%) eyes developed persistent hypotony and five eyes (19\%) required glaucoma medication. The major advantage of bleb preservation is that the bleb continues to function, in contrast to the techniques that excise the bleb. The modification we use for the current technique is to inject fibrin glue into the interface between the conjuncitval space and Tenon's/ outer bleb wall. This acts to bind the tissues together, sealing leaks and reducing the risk of hypotony, as well as reducing the potential for conjunctival flap retraction. None of our cases have required re-suturing after the initial repair as compared with previous studies. Four of the patients experienced reduced best-corrected visual acuity after the bleb repair. This was considered to be related to natural progression of advanced glaucomatous optic neuropathy. Reduced vision could also result from induced astigmatism due to tight peripheral corneal suturing. In three of our cases, needling of the bleb was required to reduce IOP's after repair. This was a routine procedure and resulted in diffuse blebs with a healthy conjunctival surface and good IOP control for the duration of the study's follow-up.

Conjunctival advancement with bleb preservation and adjunctive fibrin glue is a successful technique for bleb repair with the major advantage of preserving IOP control. This small case series compares favourably with previously documented repair techniques and was associated with no post-revision leaks, hypotony, or the need for re-suturing. If further IOP control is required, needling with 5FU can be performed with good effect. The technique can be recommended in cases of thin or leaking blebs, with sufficient healthy conjunctiva superior to the bleb.

\section{Summary}

What was known before

- Dysfunctional filtration blebs require repair and ideally result in long-term IOP control.

\section{What this study adds}

- The use of a sliding conjunctival flap preserves bleb drainage, and fibrin glue reduces the risk of flap retraction.

\section{Conflict of interest}

The authors declare no conflict of interest.

\section{References}

1 DeBry PW, Perkins TW, Heatley G, Kaufman P, Brumback LC. Incidence of late-onset bleb-related complications following trabeculectomy with mitomycin. Arch Ophthalmol 2002; 120(3): 297-300. 
2 Greenfield DS, Liebmann JM, Jee J, Ritch R. Late-onset bleb leaks after glaucoma filtering surgery. Arch Ophthalmol 1998; 116(4): 443-447.

3 Cheung JC, Wright MM, Murali S, Pederson JE. Intermediate-term outcome of variable dose mitomycin C filtering surgery. Ophthalmology 1997; 104(1): 143-149.

4 Kangas TA, Greenfield DS, Flynn Jr HW, Parrish II RK, Palmberg P. Delayed-onset endophthalmitis associated with conjunctival filtering blebs. Ophthalmology 1997; 104(5): 746-752.

5 Kosmin AS, Wishart PK. A full-thickness scleral graft for the surgical management of a late filtration bleb leak. Ophthalmic Surg Lasers 1997; 28(6): 461-468.

6 Matsuo H, Tomidokoro A, Tomita G, Araie M. Topical application of autologous serum for the treatment of late-onset aqueous oozing or point-leak through filtering bleb. Eye 2005; 19(1): 23-28.

7 Burnstein A, WuDunn D, Ishii Y, Jonescu-Cuypers C, Cantor LB. Autologous blood injection for late-onset filtering bleb leak. Am J Ophthalmol 2001; 132(1): 36-40.

8 Morris DA, Ramocki JM, Shin DH, Glover BK, Kim YY. Use of autologous Tenon's capsule and scleral patch grafts for repair of excessively draining fistulas with leaking filtering blebs. J Glaucoma 1998; 7(6): 417-419.

9 Tannenbaum DP, Hoffman D, Greaney MJ, Caprioli J. Outcomes of bleb excision and conjunctival advancement for leaking or hypotonous eyes after glaucoma filtering surgery. Br J Ophthalmol 2004; 88(1): 99-103.

10 Spencer NA, Lee C, Diamond JP. Combined conjunctival relieving incisions and advancement for the repair of lateonset leaking trabeculectomy blebs. J Glaucoma 2007; 16(4): 384-387.

11 Rauscher FM, Barton K, Budenz DL, Feuer WJ, Tseng SC. Long-term outcomes of amniotic membrane transplantation for repair of leaking glaucoma filtering blebs. $A m \mathrm{~J}$ Ophthalmol 2007; 143(6): 1052-1054.

12 Al-Shahwan S, Al-Torbak AA, Al-Jadaan I, Omran M, Edward DP. Long-term follow up of surgical repair of late bleb leaks after glaucoma filtering surgery. J Glaucoma 2006; 15(5): 432-436.

13 van de Geijn EJ, Lemij HG, de Vries J, de Waard PW. Surgical revision of filtration blebs: a follow-up study. J Glaucoma 2002; 11(4): 300-305.

14 Hamard P, Tazartes M, Ayed T, Quesnot S, Hamard H. [Prognostic outcome of leaking filtering blebs reconstruction with rotational conjunctival flaps]. J Fr Ophtalmol 2001; 24(5): 482-490.

15 Myers JS, Yang CB, Herndon LW, Allingham RR, Shields MB. Excisional bleb revision to correct overfiltration or leakage. J Glaucoma 2000; 9(2): 169-173.

16 Budenz DL, Barton K, Tseng SC. Amniotic membrane transplantation for repair of leaking glaucoma filtering blebs. Am J Ophthalmol 2000; 130(5): 580-588.

17 Budenz DL, Chen PP, Weaver YK. Conjunctival advancement for late-onset filtering bleb leaks: indications and outcomes. Arch Ophthalmol 1999; 117(8): 1014-1019.

18 Schnyder CC, Shaarawy T, Ravinet E, Achache F, Uffer S, Mermoud A. Free conjunctival autologous graft for bleb repair and bleb reduction after trabeculectomy and nonpenetrating filtering surgery. J Glaucoma 2002; 11(1): 10-16.

19 Harris LD, Yang G, Feldman RM, Fellman RL, Starita RJ, Lynn $\mathrm{J}$ et al. Autologous conjunctival resurfacing of leaking filtering blebs. Ophthalmology 2000; 107(9): $1675-1680$.
20 La Borwit SE, Quigley HA, Jampel HD. Bleb reduction and bleb repair after trabeculectomy. Ophthalmology 2000; 107(4): 712-718.

21 Buxton JN, Lavery KT, Liebmann JM, Buxton DF, Ritch R. Reconstruction of filtering blebs with free conjunctival autografts. Ophthalmology 1994; 101(4): 635-639.

22 Wilson MR, Kotas-Neumann R. Free conjunctival patch for repair of persistent late bleb leak. Am J Ophthalmol 1994; 117(5): 569-574.

23 Nagai-Kusuhara A, Nakamura M, Fujioka M, Negi A. Longterm results of amniotic membrane transplantation-assisted bleb revision for leaking blebs. Graefes Arch Clin Exp Ophthalmol 2008; 246(4): 567-571.

24 Kee C, Hwang JM. Amniotic membrane graft for late-onset glaucoma filtering leaks. Am J Ophthalmol 2002; 133(6): 834-835.

25 Ozdamar Y, Mutevelli S, Han U, Ileri D, Onal B, Ilhan O et al. A comparative study of tissue glue and vicryl suture for closing limbal-conjunctival autografts and histologic evaluation after pterygium excision. Cornea 2008; 27(5): 552-558.

26 Batman C, Ozdamar Y, Aslan O, Sonmez K, Mutevelli S, Zilelioglu G. Tissue glue in sutureless vitreoretinal surgery for the treatment of wound leakage. Ophthalmic Surg Lasers Imaging 2008; 39(2): 100-106.

27 Bahar I, Weinberger D, Gaton DD, Avisar R. Fibrin glue versus vicryl sutures for primary conjunctival closure in pterygium surgery: long-term results. Curr Eye Res 2007; 32(5): 399-405.

28 Mentens R, Devogelaere T, Stalmans P. Comparing fibrin glue to sutures for conjunctival closure in pars plana vitrectomy. Bull Soc Belge Ophtalmol 2007; (306): 49-56.

29 Shoham A, Tessler Z, Finkelman Y, Lifshitz T. Large soft contact lenses in the management of leaking blebs. CLAO J 2000; 26(1): 37-39.

30 Porges Y, Ophir A. Hollow bandage contact lens. Ophthalmic Surg Lasers 2001; 32(2): 124-128.

31 Jonas JB, Dugrillon A, Kluter H, Kamppeter B. Subconjunctival injection of autologous platelet concentrate in the treatment of overfiltrating bleb. J Glaucoma 2003; 12(1): 57-58.

32 Hennis HL, Stewart WC. Use of the argon laser to close filtering bleb leaks. Graefes Arch Clin Exp Ophthalmol 1992; 230(6): 537-541.

33 Lynch MG, Roesch M, Brown RH. Remodeling filtering blebs with the neodymium:YAG laser. Ophthalmology 1996; 103(10): 1700-1705.

34 Geyer O. Management of large, leaking, and inadvertent filtering blebs with the neodymium:YAG laser. Ophthalmology 1998; 105(6): 983-987.

35 Leen MM, Moster MR, Katz LJ, Terebuh AK, Schmidt CM, Spaeth GL. Management of overfiltering and leaking blebs with autologous blood injection. Arch Ophthalmol 1995; 113(8): 1050-1055.

36 Smith MF, Magauran R, Doyle JW. Treatment of postfiltration bleb leak by bleb injection of autologous blood. Ophthalmic Surg 1994; 25(9): 636-637.

37 O'Connor DJ, Tressler CS, Caprioli J. A surgical method to repair leaking filtering blebs. Ophthalmic Surg 1992; 23(5): 336-338.

38 Dunnington JH, Regan EF. Late fistlization of operative wounds. Arch Ophthalmol 1950; 43: 407-418.

39 Catoira Y, Wudunn D, Cantor LB. Revision of dysfunctional filtering blebs by conjunctival advancement with bleb preservation. Am J Ophthalmol 2000; 130(5): 574-579. 